\title{
Theoretical Analysis on Distribution Pattern of Plastic Zone in Surrounding Rock of High-Gas-Coal Roadway
}

\author{
Chao Yuan $\left(\mathbb{D},{ }^{1,2,3}\right.$ Liming Cao, ${ }^{3}$ Lei Fan, ${ }^{3}$ and Jianqiang Guo ${ }^{3}$ \\ ${ }^{1}$ Work Safety Key Lab on Prevention and Control of Gas and Roof Disasters for Southern Coal Mines, \\ Hunan University of Science and Technology, Xiangtan 411201, China \\ ${ }^{2}$ Hunan Provincial Key Laboratory of Safe Mining Techniques of Coal Mines, Hunan University of Science and Technology, \\ Xiangtan 411201, China \\ ${ }^{3}$ School of Resources, Environment and Safety Engineering, Hunan University of Science and Technology, Xiangtan 411201, China
}

Correspondence should be addressed to Chao Yuan; yuanchaozh1@126.com

Received 8 December 2020; Revised 3 January 2021; Accepted 26 February 2021; Published 9 March 2021

Academic Editor: Alessandro Palmeri

Copyright (c) 2021 Chao Yuan et al. This is an open access article distributed under the Creative Commons Attribution License, which permits unrestricted use, distribution, and reproduction in any medium, provided the original work is properly cited.

The formation and expansion of the plastic zone is always accompanied by the deformation and failure of the roadway-surrounding rock. Based on elastoplastic theory, this paper considers the gas pressure parameters and uses the Mohr-Coulomb strength criterion to derive the implicit equation of the plastic zone boundary in the rock surrounding gas-coal roadways. The distribution characteristics of the plastic zone of gas-coal roadway-surrounding rock are studied, and the sensitivity to the gas pressure, cohesion, internal friction angle, and support strength of the roadway free face on the plastic zone of the surrounding rock is analyzed. The research results show that the plastic zone of the surrounding rock has four distribution patterns: circular, elliptical, rounded rectangle, and butterfly. Additionally, the lateral pressure coefficient, gas pressure, cohesion, and internal friction angle are found to jointly determine the distribution and range of the plastic zone. However, the support strength of the roadway free face does not change the distribution of the plastic zone but only affects its range. The circular and elliptical plastic zones are less sensitive to gas pressure, cohesion, and internal friction angle, whereas butterfly-shaped plastic zones are highly sensitive to these factors. The main manifestation of this sensitivity is that the four butterfly leaves degenerate rapidly with any decrease in the gas pressure or increase in the cohesion and internal friction angle. Larger butterfly leaves are prone to faster degeneration. The research results presented in this paper have important theoretical guiding significance and engineering application value for the design of high-gas-coal roadway support and gas drilling.

\section{Introduction}

Gas-rich coal has an unstable structure, low degree of cementation, and significant variations in particle size and adsorption characteristics. These characteristics lead to a decrease in the overall strength and stability of the surrounding rock of gas-coal roadways, leaving them vulnerable to disturbances such as mining activities. Part of the coal body enters a pressurized state from the original stress state, and its internal cracks shrink and close, causing the gas pressure to increase [1-3]. Under the influence of multiple factors (e.g., high ground stress, mining, and gas pressure), the surrounding rock of gas-coal roadways exhibits a series of engineering response characteristics during service periods, such as asymmetry and large-scale instability failures. Roof and patchwork disasters frequently occur. This represents a great threat to safe production, and so the prevention and control of deformation and instability of surrounding rock in gas-coal roadways are of great importance. However, the increasing complexity of the coal seam environment and the increasing intensity of mining make the control of gas-coal roadway stability more difficult. Therefore, we need to fully understand the mechanism of the deformation and failure of surrounding rock in gas-coal roadways. This is the basis and key to the scientific design of roadway-surrounding rock and the prevention and control of various geological disasters. 
There has been considerable research on the deformation and failure mechanism of surrounding rock in roadways. The formation and expansion of the plastic zone is always accompanied by the deformation and failure of the surrounding rock of the roadway, and the plastic zone is used as the main basis for analyzing the deformation and failure mode of the roadway-surrounding rock [4]. Zareifard and Fahimifar derived analytical solutions for the stress and displacement of the surrounding rock of a circular roadwaysurrounding rock and found that the distribution of the plastic zone under a uniform stress field has a significant influence on its stability [5]. Based on the deviatoric stress theory of elastoplastic mechanics, Ma et al. found analytical solutions for the deviatoric stress of the rock surrounding a circular roadway under a nonuniform stress field and developed a calculation method for the radius of the plastic zone, which showed that the distribution of the plastic zone is closely related to the deviator correlation and irregular distribution [6]. Using the Hoek-Brown strength criterion, Xia et al. derived an analytical expression for the plastic zone of the surrounding rock of a circular roadway considering the strain-softening characteristics [7]. Zhao et al. derived theoretical calculation formulas for the radius and stress field of the plastic zone of a circular roadway-surrounding rock based on the humidity stress field and elastoplastic theory. The influence of the roadway-surrounding rock humidity and support strength on the plastic zone of the surrounding rock was analyzed, and the accuracy of the humidity distribution function and radius of the plastic zone was verified by field tests [8]. Liu et al. analyzed the plastic zone range of the surrounding rock in shallow tunnels from an energy perspective and divided the development process of the plastic zone into three stages: (1) formation and expansion of the plastic zone; (2) connection of the plastic zone; and (3) extension of the plastic zone to the surface [9]. Zhou and Li used the nonlinear Hoek-Brown failure criterion to derive analytical solutions for the plastic zone of circular roadway-surrounding rock considering the magnitude of ground stress. The influence of horizontal in situ stress, vertical in situ stress, and rock mass strength parameters on the distribution of the plastic zone in the surrounding rock was analyzed [10]. Ma et al. studied the shape and size of the plastic zone around a deeply buried double circular tunnel and analyzed the effects of tunnel spacing, ground stress, cohesion, and internal friction angle on the plastic zone [11]. Zhou et al. found that the plastic zone enhances the effective permeability of gas-rich coal seams through engineering field investigations [12]. Zhao et al. used COMSOL to simulate the gas pressure distribution around a roadway and found that the plastic zone is the main channel for gas flow [13]. Liu et al. investigated the effect of the plastic zone on the quality of gas extraction and found that a larger plastic zone can significantly improve gas extraction, thus preventing spontaneous coal combustion, gas explosion, and other disasters [14]. Zhang et al. used FLAC 3D software to analyze the stress state and deformation law of a coal body after roadway excavation and drilling. They determined the distribution range of the plastic and elastic zones and studied the permeability of the coal near the drilling site [15]. Zhang et al. combined the noncorrelated flow law and the Hoek-Brown criterion and used an FVP model to derive an analytical solution for the viscoplastic deformation of a circular roadway-surrounding rock. The variation of the displacement of the viscoplastic zone with respect to depth has been analyzed, providing a rapid evaluation of the viscoplastic deformation of the roadway-surrounding rock in the early design process [16]. $\mathrm{Xu}$ et al. derived an analytical solution for the plastic zone around a noncircular tunnel based on the Mohr-Coulomb criterion and the theory of complex variables. The influence of the lateral pressure coefficient and the depth of the pressure relief hole on the plastic zone of the tunnel-surrounding rock was discussed [17]. Kabwe et al. derived an elastoplastic analytical solution for noncircular tunnelsurrounding rock considering the intermediate principal stress based on the equivalent radius function and the Drucker-Prager yield criterion. The analytical solution can better predict the plastic zone range of the rock surrounding the tunnel and the degree of convergent deformation of the tunnel, enabling the design of an appropriate tunnel support structure [18].

Analysis of the above results shows that researchers have generally used the plastic zone as an important indicator for theoretical analysis, numerical simulations, and engineering test results when evaluating the rock surrounding a roadway. However, little research has focused on the plastic zone itself, and the influence of the gas pressure, original rock stress, rock mass strength, and support strength on the plastic zone of coal roadway-surrounding rock has rarely been considered. Thereby, it is impossible to truly reflect the deformation and failure instability mechanism of the surrounding rock of gas-coal roadways, making it impossible to propose an effective surrounding-rock support strategy. Therefore, based on elastoplastic theory and Mohr-Coulomb strength theory, this paper derives the implicit equation for the boundary of the plastic zone of the roadway-surrounding rock considering the gas pressure. Using theoretical analysis, the influence of the lateral pressure coefficient, gas pressure, cohesion, internal friction angle, and support strength of the roadway's free face on the distribution morphology of the plastic zone of the roadway-surrounding rock is examined. The research results have important theoretical guiding significance for the reinforcement of the surrounding rock of gas-coal roadways.

\section{Description and Hypothesis of Mechanical Model of Surrounding Rock in Coal Roadway}

In the vertical direction, the original rock stress is $P_{1}$, the horizontal direction of the original rock stress is $P_{3}$, and the pore gas pressure is $P_{g}$, and the excavation radius is a circular section of roadway. The supporting force acting on the roadway wall is $P_{i}$, and the gas pore pressure is $P_{a}$. Taking the unit length along the axis of the roadway, we have an axisymmetric plane strain problem, assuming that the physical strength can be ignored.

To analyze the stress state of the surrounding rock in a disequilibrium circular roadway, the mechanical model of 
the surrounding rock of the roadway must be simplified accordingly. Thus, the bidirectional stress field is regarded as a uniform load, and the following basic assumptions are made:

(1) The section of the roadway is circular, with radius a and buried depth $H \geq 20 a$, and is an infinitely long flat roadway.

(2) The surrounding rock mass of the roadway is an isotropic medium, forming an ideal elastic-plastic body.

(3) The surrounding rock of the roadway is in a nonuniform high-stress environment.

(4) The external boundary condition of the calculation model is the vertical principal stress $P_{1}$ and the horizontal principal stress $P_{3}$, both of which are parallel to the Cartesian coordinate axes.

Based on this, the mechanical model of the surrounding rock of circular roadway is established as shown in Figure 1.

\section{Gas Pressure Distribution in Rock Surrounding a Coal Roadway}

After the excavation of the roadway, the gas flow in the surrounding rock has the form of axisymmetric radial seepage. The gas flow rate $Q$ through a cylindrical area of unit length and radius $r$ per unit time is

$$
Q=-2 \pi r K \frac{\mathrm{d} p}{\mathrm{~d} r},
$$

where $p$ is the pore gas pressure at radius $r$ and $K$ is the permeability coefficient.

Integrating equation (1) gives

$$
p(r)=c_{1}-\frac{Q}{2 \pi K} \ln .
$$

From equation (2) and the boundary conditions $p(a)=$ $P_{a}, p(b)=P_{g}$, we have

$$
\begin{aligned}
c_{1} & =P_{a}+\frac{Q}{2 \pi K} \ln a, \\
\frac{Q}{2 \pi K} & =\frac{P_{g}-P_{a}}{\ln (a / b)} .
\end{aligned}
$$

Substituting equations ( $3 a$ ) and ( $3 b$ ) into equation (2) for the gas pressure distribution leads to

$$
\begin{aligned}
p(r) & =P_{a}+\frac{\left(P_{g}-P_{a}\right) \ln (a / r)}{\ln (a / b)}, \\
\frac{\mathrm{d} p}{\mathrm{~d} r} & =-\frac{\left(P_{g}-P_{a}\right)}{r \ln (a / b)} .
\end{aligned}
$$

\section{Theoretical Solution of Plastic Zone around a Coal Roadway}

The circular roadway model in Figure 2 is decomposed into two parts under the action of the initial ground stress and gas pressure: the first part is the uniform stress field condition, which bears the gas pressure effect, as shown in Figure 2(a); the second part does not consider the gas pressure, but the vertical and horizontal directions are subjected to equal compression and tensile stress, respectively, as shown in Figure 2(b).

\subsection{Theoretical Solution of Stress Field in Elastic Zone of Rock Surrounding a Coal Roadway}

4.1.1. First Part of the Theoretical Solution of the Surrounding Rock under the Uniform Stress Field (Figure 2(a)). For rock materials, the modified Terzaghi effective stress principle indicates that the relationship between the effective stress $\sigma_{i j}^{\prime}$ acting on the coal skeleton and the pore gas pressure $p$ is

$$
\sigma_{i j}^{\prime}=\sigma_{i j}-v p \delta_{i j},
$$

where $\sigma_{i j}^{\prime}$ is the effective stress tensor, $\sigma_{i j}$ is the stress tensor generated by the external load, $p$ is the pore gas pressure, $v$ is the effective stress coefficient, and $\delta_{i j}$ is the Kronecker delta function

$$
\left.\begin{array}{l}
\sigma_{r}^{\prime}=\sigma_{r}-v p \\
\sigma_{\theta}^{\prime}=\sigma_{\theta}-v p
\end{array}\right\}
$$

The equilibrium equation for the axisymmetric plane strain problem under the condition of neglecting the surrounding rock mass of the roadway is

$$
\frac{\mathrm{d} \sigma_{r}}{\mathrm{~d} r}+\frac{\sigma_{r}-\sigma_{\theta}}{r}=0
$$
gives

Substituting Equations (4b) and (6) into Equation (7)

$$
\frac{\mathrm{d} \sigma_{r}^{\prime}}{\mathrm{d} r}-\frac{v\left(P_{g}-P_{a}\right)}{r \ln (a / b)}+\frac{\sigma_{r}^{\prime}-\sigma_{\theta}^{\prime}}{r}=0 .
$$

Setting

$$
\frac{v\left(P_{g}-P_{a}\right)}{\ln (a / b)}=A,
$$

allows equation (8) to be expressed as

$$
\frac{\mathrm{d} \sigma_{r}^{\prime}}{\mathrm{d} r}+\frac{\sigma_{r}^{\prime}-\sigma_{\theta}^{\prime}}{r}-A=0
$$

Let the radial strain component be $\varepsilon_{r}$, the hoop strain component $\varepsilon_{\theta}$, and the radial displacement $u$. Then, the geometric equation is 


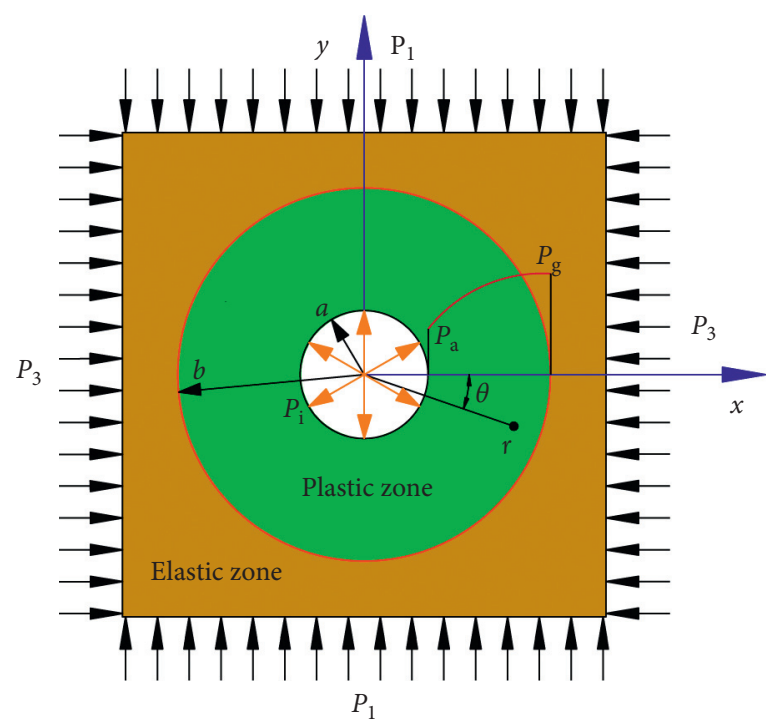

FIgUre 1: Mechanical model of roadway.

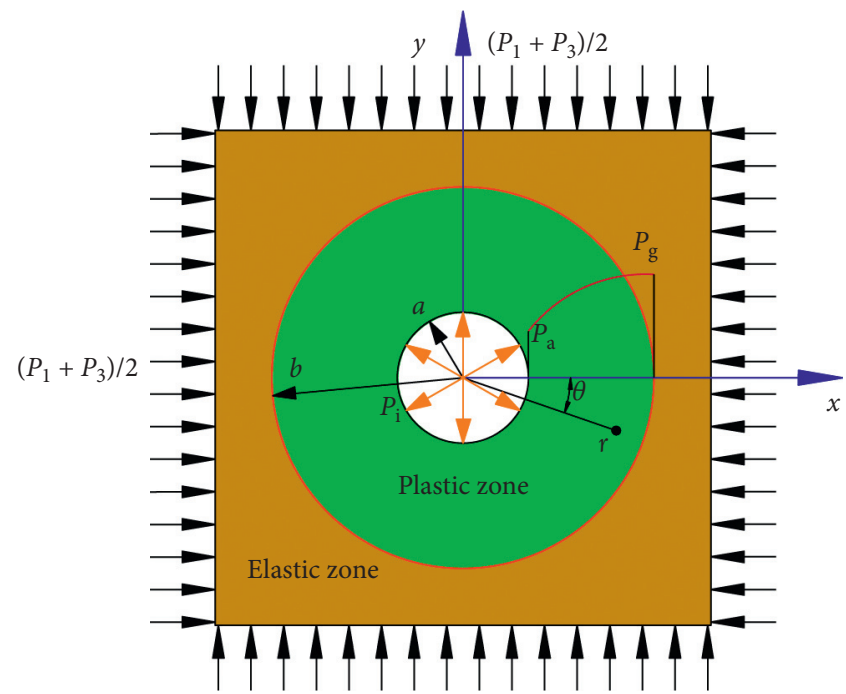

(a)

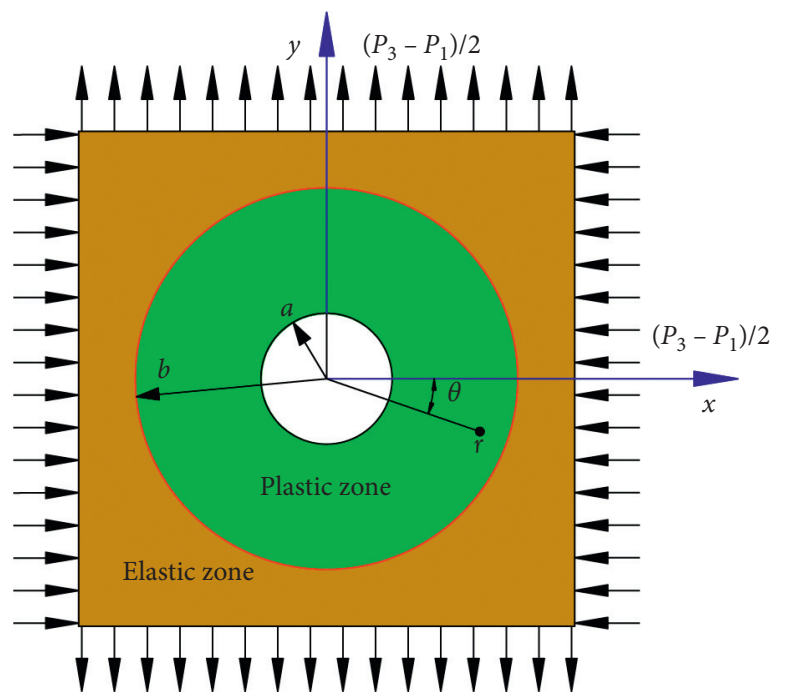

(b)

FIGURE 2: Decomposition of surrounding rock pressure for roadway.

$$
\left.\begin{array}{c}
\varepsilon_{r}=\frac{\mathrm{d} u}{\mathrm{~d} r} \\
\varepsilon_{\theta}=\frac{u}{r} \\
\gamma_{r \theta}=0
\end{array}\right\} .
$$

In the elastic region, the stress-strain relationship is

$$
\left.\begin{array}{l}
\varepsilon_{r}=\frac{1-\mu^{2}}{E}\left(\sigma_{r}^{\prime}-\frac{\mu}{1-\mu} \sigma_{\theta}^{\prime}\right) \\
\varepsilon_{\theta}=\frac{1-\mu^{2}}{E}\left(\sigma_{\theta}^{\prime}-\frac{\mu}{1-\mu} \sigma_{r}^{\prime}\right) \\
\gamma_{r \theta}=\tau_{r \theta}=0
\end{array}\right\} .
$$


Set

$$
\left.\begin{array}{l}
m=\frac{1-\mu^{2}}{E} \\
n=\frac{\mu}{1-\mu}
\end{array}\right\}
$$

We can write Equation (12) as

$$
\left.\begin{array}{l}
\sigma_{r}^{\prime}=\frac{1}{m-m n^{2}}\left(\varepsilon_{r}+n \varepsilon_{\theta}\right) \\
\sigma_{\theta}^{\prime}=\frac{1}{m-m n^{2}}\left(n \varepsilon_{r}+\varepsilon_{\theta}\right)
\end{array}\right\} .
$$

Taking the derivative of Equation (14) gives

$$
\left.\begin{array}{c}
\frac{\mathrm{d} \sigma_{r}^{\prime}}{\mathrm{d} r}=\frac{1}{m-m n^{2}}\left(\frac{d \varepsilon_{r}}{d r}+\frac{n d \varepsilon_{\theta}}{d r}\right) \\
\frac{\sigma_{r}^{\prime}-\sigma_{\theta}^{\prime}}{r}=\frac{\varepsilon_{r}-n \varepsilon_{r}+n \varepsilon_{\theta}-\varepsilon_{\theta}}{r\left(m-m n^{2}\right)}
\end{array}\right\} .
$$

Substituting Equation (15) into Equation (11) yields

$$
\left.\begin{array}{l}
\frac{\mathrm{d} \sigma_{r}^{\prime}}{\mathrm{d} r}=\frac{1}{m-m n^{2}}\left(\frac{\mathrm{d}^{2} u}{\mathrm{~d} r^{2}}+\frac{n \mathrm{~d} u}{r \mathrm{~d} r}-\frac{n u}{r^{2}}\right) \\
\frac{\sigma_{r}^{\prime}-\sigma_{\theta}^{\prime}}{r}=\frac{(1-n)}{r\left(m-m n^{2}\right)} \frac{\mathrm{d} u}{\mathrm{~d} r}+\frac{(n-1) u}{r^{2}\left(m-m n^{2}\right)}
\end{array}\right\} .
$$

And substituting Equation (16) into Equation (8) gives

$$
\frac{\mathrm{d}^{2} u}{\mathrm{~d} r^{2}}+\frac{1}{r} \frac{d u}{d r}-\frac{u}{r^{2}}-\frac{A\left(m-m n^{2}\right)}{r}=0 .
$$

Solving this differential equation, we obtain

$$
u=c_{1} r+\frac{c_{2}}{r}+\frac{A\left(m-m n^{2}\right) r \ln r}{2} .
$$

Substituting Equation (18) into Equation (11), we then have that

$$
\left.\begin{array}{l}
\varepsilon_{r}=c_{1}-\frac{c_{2}}{r^{2}}+\frac{A\left(m-m n^{2}\right) \ln r}{2}+\frac{A\left(m-m n^{2}\right)}{2} \\
\varepsilon_{\theta}=c_{1}+\frac{c_{2}}{r^{2}}+\frac{A\left(m-m n^{2}\right) \ln r}{2}
\end{array}\right\},
$$

which can be substituted into Equation (14) to give

$$
\left.\begin{array}{l}
\sigma_{r}^{\prime}=\frac{1}{m-m n^{2}}\left[(1+n) c_{1}+(n-1) \frac{c_{2}}{r^{2}}+\frac{A(1+n)\left(m-m n^{2}\right) \ln r}{2}+\frac{A\left(m-m n^{2}\right)}{2}\right] \\
\sigma_{\theta}^{\prime}=\frac{1}{m-m n^{2}}\left[\left(n_{1}+1\right) c_{1}+\frac{(1-n) c_{2}}{r^{2}}+\frac{A(n+1)\left(m-m n^{2}\right) \ln r}{2}+\frac{A n\left(m-m n^{2}\right)}{2}\right]
\end{array}\right\} .
$$

For $r=a$ and $r=b$, we can write

Substituting Equation (20) into Equation (21) then yields

$$
\left.\begin{array}{c}
\left.\sigma_{r}\right|_{r=a}=P_{i}-v P_{a} \\
\left.\sigma_{r}\right|_{r=b}=\frac{P_{3}+P_{1}}{2}-v P_{g}
\end{array}\right\} .
$$

$$
\left.\begin{array}{l}
c_{2}=\frac{T\left(m-m n^{2}\right) a^{2} b^{2}}{\left(b^{2}-a^{2}\right)(n-1)}-\frac{S\left(m-m n^{2}\right) a^{2} b^{2}}{\left(b^{2}-a^{2}\right)(n-1)}-\frac{A a^{2} b^{2}(1+n)\left(m-m n^{2}\right) \ln (a / b)}{2\left(b^{2}-a^{2}\right)(n-1)} \\
\left.c_{1}=\frac{T\left(m-m n^{2}\right)}{(1+n)}-\frac{T\left(m-m n^{2}\right) b^{2}}{\left(b^{2}-a^{2}\right)(1+n)}+\frac{S\left(m-m n^{2}\right) b^{2}}{\left(b^{2}-a^{2}\right)(1+n)}-\frac{A\left(m-m n^{2}\right) \ln a}{2}-\frac{A\left(m-m n^{2}\right)}{2(1+n)}+\frac{A b^{2}\left(m-m n^{2}\right) \ln (a / b)}{2\left(b^{2}-a^{2}\right)}\right\}
\end{array}\right\}
$$


where

$$
\left.\begin{array}{l}
T=P_{i}-v P_{a} \\
S=\frac{P_{3}+P_{1}}{2}-v P_{g}
\end{array}\right\} .
$$

Substituting Equation (22) into Equation (20), the stress expression in the elastic phase is

$$
\left.\begin{array}{l}
\sigma_{r}^{\prime}=\frac{\left(b^{2}-r^{2}\right) T a^{2}}{\left(b^{2}-a^{2}\right) r^{2}}+\frac{\left(r^{2}-a^{2}\right) S b^{2}}{\left(b^{2}-a^{2}\right) r^{2}}+\frac{A(1+n)}{2}\left[\frac{\left(r^{2}-a^{2}\right) b^{2} \ln (a / b)}{\left(b^{2}-a^{2}\right) r^{2}}+\ln r-\ln a\right] \\
\sigma_{\theta}^{\prime}=-\frac{\left(r^{2}+b^{2}\right) T a^{2}}{\left(b^{2}-a^{2}\right) r^{2}}+\frac{\left(a^{2}+r^{2}\right) S b^{2}}{\left(b^{2}-a^{2}\right) r^{2}}+\frac{A(n+1)}{2}\left[\frac{\left(r^{2}+a^{2}\right) b^{2} \ln (a / b)}{\left(b^{2}-a^{2}\right) r^{2}}+\ln r-\ln a\right]
\end{array}\right\} .
$$

If $b$ is much larger than $a$, Equation (24) can be approximated as

$$
\left.\begin{array}{l}
\sigma_{r}^{\prime}=\frac{T a^{2}}{r^{2}}+\left(1-\frac{a^{2}}{r^{2}}\right) S+\left[\frac{a(1+n)\left(P_{g}-P_{a}\right)}{2}\left(1-\frac{a^{2}}{r^{2}}\right)\right] \\
\sigma_{\theta}^{\prime}=-\frac{T a^{2}}{r^{2}}+\left(1+\frac{a^{2}}{r^{2}}\right) S+\left[\frac{a(1+n)\left(P_{g}-P_{a}\right)}{2}\left(1+\frac{a^{2}}{r^{2}}\right)\right]
\end{array}\right\} .
$$

4.1.2. Second Part of the Theoretical Solution for the Surrounding Rock Stress Field of the Roadway under Pressure and Tensile Stress Field (Figure 2(b)). When $r=b$, we can write

$$
\left.\begin{array}{c}
\left.\sigma_{r}\right|_{r=b}=-\frac{P_{3}-P_{1}}{2} \cos 2 \theta \\
\left.\tau_{r \theta}\right|_{r=b}=\frac{P_{3}-P_{1}}{2} \sin 2 \theta
\end{array}\right\} .
$$

Obviously, the stress solution is related to $r$ and $2 \theta$, and the stress function is

$$
y=f(r) \cos 2 \theta .
$$

Substituting Equation (27) into the biharmonic equation, and recalling the boundary conditions $r=a, \sigma_{r}=0$, $\tau_{r \theta}=0$, the elastic phase stress expression is

$$
\left.\begin{array}{l}
\sigma_{r}=W \cos 2 \theta\left(1-\frac{a^{2}}{r^{2}}\right)\left(1-\frac{3 a^{2}}{r^{2}}\right) \\
\sigma_{\theta}=-W \cos 2 \theta\left(1+\frac{3 a^{4}}{r^{4}}\right) \\
\tau_{r \theta}=-W \sin 2 \theta\left(1-\frac{a^{2}}{r^{2}}\right)\left(1+\frac{3 a^{2}}{r^{2}}\right)
\end{array}\right\},
$$

where

$$
W=\frac{\left(P_{3}-P_{1}\right)}{2}
$$

In the above expressions, $\tau_{r \theta}$ is the shear stress of a point in the surrounding rock of the roadway in polar coordinates, and $\theta$ is the polar coordinate of this point. 
4.1.3. Theoretical Solution of Surrounding Rock Stress Field in Gas-Coal Roadway. The first and second partial stress components are superimposed; that is, Equations (25) and (28) are added together to obtain the theoretical solution for the elastic stress field of the surrounding rock of a gas-coal roadway under the condition of a nonuniform stress field. The specific expression is as follows:

$$
\left.\begin{array}{l}
\sigma_{r}^{\prime}=W \cos 2 \theta\left(1-\frac{a^{2}}{r^{2}}\right)\left(1-\frac{3 a^{2}}{r^{2}}\right)+\left(1-\frac{a^{2}}{r^{2}}\right) S+\frac{T a^{2}}{r^{2}}+\left[\frac{v(1+n)\left(P_{g}-P_{a}\right)}{2}\left(1-\frac{a^{2}}{r^{2}}\right)\right] \\
\sigma_{\theta}^{\prime}=-W \cos 2 \theta\left(1+\frac{3 a^{4}}{r^{4}}\right)+\left(1+\frac{a^{2}}{r^{2}}\right) S-\frac{T a^{2}}{r^{2}}+\left[\frac{v(1+n)\left(P_{g}-P_{a}\right)}{2}\left(1+\frac{a^{2}}{r^{2}}\right)\right] \\
\tau_{r \theta}=-W \sin 2 \theta\left(1-\frac{a^{2}}{r^{2}}\right)\left(1+\frac{3 a^{2}}{r^{2}}\right)
\end{array}\right\} .
$$

4.2. Theoretical Solution of Stress Field in Plastic Zone of Rock Surrounding a Coal Roadway. When the stress in the surrounding rock of the roadway is greater than the strength of the rock mass, the surrounding rock undergoes plastic deformation, and a plastic deformation zone appears in the surrounding rock from the free face of the roadway. At this time, the surrounding rock stress satisfies the Mohr-Coulomb yield criterion [19], namely,

$$
\frac{\left(\sigma_{r}^{\prime}-\sigma_{\theta}^{\prime}\right)^{2}}{4}+\tau_{r \theta}^{2}=\left[\frac{\left(\sigma_{r}^{\prime}+\sigma_{\theta}^{\prime}\right)^{2}}{4}-c^{2}\right] \frac{(1-\cos 2 \varphi)}{2}+\frac{\left(\sigma_{r}^{\prime}+\sigma_{\theta}^{\prime}\right)}{2} c \sin 2 \varphi+c^{2}
$$

where $c$ is the cohesion $[\mathrm{MPa}]$ and $\varphi$ is the internal friction angle $\left[^{\circ}\right]$.

Let the boundary of the plastic zone be $r$, and set $P_{3}=\lambda P_{1}$. derive the boundary stealth equation of the plastic zone of the circular roadway-surrounding rock around $r, \theta$, namely, Now, bringing Equation (31) into Equation (30), we can

$$
\begin{aligned}
f(r, \theta)= & \left\{P_{1}(\lambda-1) \cos 2 \theta\left(1-\frac{2 a^{2}}{r^{2}}+\frac{3 a^{4}}{r^{4}}\right)-\frac{a^{2}\left(\lambda P_{1}+P_{1}-2 v P_{g}\right)}{r^{2}}+\frac{2 a^{2}\left(P_{i}-v P_{a}\right)}{r^{2}}-\frac{a^{2}\left[\left(v\left(P_{g}-P_{a}\right) / 1-\mu\right)-2 v P_{g}\right]}{r^{2}}\right\}^{2} \\
& +\left[P_{1}(\lambda-1) \sin 2 \theta\left(1+\frac{2 a^{2}}{r^{2}}-\frac{3 a^{4}}{r^{4}}\right)\right]^{2}-\frac{(1-\cos 2 \varphi)}{2}\left\{\left[P_{1}(\lambda+1)-\frac{2 P_{1}(\lambda-1) a^{2} \cos 2 \theta}{r^{2}}-4 v P_{g}+\frac{v\left(P_{g}-P_{a}\right)}{1-\mu}\right]^{2}-4 c^{2}\right\} \\
& -2 c \sin 2 \varphi\left[P_{1}(\lambda+1)-\frac{2 P_{1}(\lambda-1) a^{2} \cos 2 \theta}{r^{2}}-4 v P_{g}+\frac{v\left(P_{g}-P_{a}\right)}{1-\mu}\right]-4 c^{2} .
\end{aligned}
$$

The point at which $f(r, \theta)=0$ is the boundary line between the elastic zone and the plastic zone of the surrounding rock of the circular roadway, that is, the boundary equation of the plastic zone. If $\lambda=1$, then the radius of the plastic zone of the circular roadway-surrounding rock under the normal uniform stress field can be obtained from Equation (32) as

$$
\begin{aligned}
f(r, \theta)= & \left\{\frac{2 a^{2}\left(P_{i}-v P_{a}\right)}{r^{2}}-\frac{2 a^{2}\left(P_{1}-v P_{g}\right)}{r^{2}}-\frac{a^{2}\left[\left(v\left(P_{g}-P_{a}\right) / 1-\mu\right)-2 v P_{g}\right]}{r^{2}}\right\}^{2} \\
& -\frac{(1-\cos 2 \varphi)}{2}\left\{\left[2 P_{1}-4 v P_{g}+\frac{v\left(P_{g}-P_{a}\right)}{1-\mu}\right]^{2}-4 c^{2}\right\}-2 c \sin 2 \varphi\left[2 P_{1}-4 v P_{g}+\frac{v\left(P_{g}-P_{a}\right)}{1-\mu}\right]-4 c^{2} .
\end{aligned}
$$




\section{Factors Affecting the Theoretical Solution for the Plastic Zone Surrounding a Coal Roadway}

We now analyze the influence of the lateral pressure coefficient, gas pressure, support strength, surrounding rock cohesion, and internal friction angle on the plastic zone boundary. According to Equation (32), the circular roadway is calculated using MATLAB, and the boundary of the surrounding rock plastic zone approximates a curve.

\subsection{Influence of Lateral Pressure Coefficient on Plastic Zone of} Rock Surrounding a Coal Roadway. Figure 3 shows the approximate curve of the plastic zone boundary of the circular roadway-surrounding rock under different lateral pressure coefficients, where $P_{1}=19 \mathrm{MPa}, c=3 \mathrm{MPa}, \varphi=25^{\circ}$, $\mu=0.3, a=2 \mathrm{~m}, P_{i}=0 \mathrm{MPa}, P_{a}=P_{g}=0 \mathrm{MPa}$, and $v=0$.

It can be seen from Figure 3 that when the lateral pressure coefficient is equal to 1 , the distribution pattern of the surrounding plastic zone of the circular roadway-surrounding rock under the uniform stress field is circular. As the lateral pressure coefficient increases, the distribution pattern of the plastic zone changed from circular to elliptical, and then a rounded rectangle, before finally forming a butterfly shape with four symmetrical butterfly leaves. Once the plastic zone of the roadway forms a butterfly shape, further increases in the lateral pressure coefficient cause the four butterfly leaves in the plastic zone to expand.

To describe the relationship between the lateral pressure coefficient and the plastic zone range of the roadway-surrounding rock, the relationship between the lateral pressure coefficient $\lambda$ and the effective radius (maximum radius, see Figure 4) $R$ of the plastic zone is plotted in Figure 5. Larger values of the effective radius $R$ result in more severe plastic failure of the surrounding rock in the direction of the radius. For ease of description, the plastic zone radii discussed below all refer to the effective radius.

It can be seen from Figure 5 that increasing the lateral pressure coefficient causes the radius of the plastic zone to increase. According to the difference in the growth rate of the radius of the plastic zone, the process can be divided into two stages. In the first stage, when the lateral pressure coefficient is small, the radius of the plastic zone increases slowly with respect to the lateral pressure coefficient in an approximately linear manner. The growth rate at this stage is less sensitive to changes in the lateral pressure coefficient. For example, when the lateral pressure coefficient increases from 1.6 to 1.9 , the radius of the plastic zone only increases by $0.5 \mathrm{~m}$. The distribution of the plastic zone at this stage mainly transitions from circular $\longrightarrow$ ellipse $\longrightarrow$ rounded rectangle.

As the lateral pressure coefficient continues to increase, the sensitivity of the plastic zone radius to the lateral pressure coefficient increases rapidly, and the growth rate of the plastic zone radius increases rapidly, entering the second stage. The growth mode of the radius of the plastic zone in the second stage is mainly manifested in the nonlinear growth of the butterfly leaves in the plastic zone, with the distribution of the plastic zone rapidly expanding in a butterfly shape. For example, when the lateral pressure coefficient increases from 2.5 to 2.8 , the radius of the plastic zone increases from 6.4 to $12.5 \mathrm{~m}$. This demonstrates that the plastic yield failure of the surrounding rock mass in this range is extremely sensitive to the lateral pressure coefficient-even if the lateral pressure coefficient does not change by much, it may cause localized deformation and failure of the surrounding rock. Through field investigations and a literature search $[20,21]$, it is apparent that many underground roadways are in high-ground-stress areas with relatively large lateral pressure coefficients, leading to butterfly plastic zones around the roadways. The formation and nonlinear expansion of the butterfly plastic zone also theoretically proves that the two top and bottom corners of the roadway obtained from field investigations often suffer from shear deformation and failure. At the same time, it is clear that this type of roadway undergoes greater deformation than ordinary roadways and has features that are more difficult to control.

5.2. Influence of Gas Pressure on Plastic Zone of Rock Surrounding a Coal Roadway. Figure 6 shows approximate curves of the plastic zone boundary of the circular roadwaysurrounding rock under different gas pressures, where $P_{1}=19 \mathrm{MPa}, c=3 \mathrm{MPa}, \varphi=25^{\circ}, \mu=0.3, a=2 \mathrm{~m}, P_{i}=0 \mathrm{MPa}$, $P_{a}=0 \mathrm{MPa}$, and $v=0.5$; the other parameters are unchanged from the previous subsection.

It can be seen from Figures 6(a) and 6(b) that when the plastic zone of the surrounding rock of the roadway is circular or elliptical, that is, when the lateral pressure coefficient is small, changes in the gas pressure have little effect on the distribution pattern of the plastic zone. As shown in Figure 6(c), when the gas pressure is $7.0 \mathrm{MPa}$, the plastic zone of the roadway-surrounding rock presents an approximate butterfly shape, while the shape of the plastic zone when the gas pressure is reduced to $0.0 \mathrm{MPa}$ is a rounded rectangle. That is, a reduction in the gas pressure can promote the transformation of the distribution form of the plastic zone from an approximate butterfly shape to a rounded rectangle. The plastic zone expands slightly in the horizontal direction as the gas pressure decreases, while the plastic zone remains almost unchanged in the vertical direction.

For the butterfly-shaped plastic zone, when the gas pressure is large, the four butterfly leaves are extremely sensitive to the gas pressure and rapidly degrade as the gas pressure decreases. The sensitivity of the butterfly leaves to the gas pressure in the plastic zone gradually weakens, and the nonlinear relationship between the two gradually changes to an approximately linear relationship, as shown in Figure 6(d). If the gas pressure decreases from 6.75 to $5.75 \mathrm{MPa}$, the radius of the plastic zone decreases rapidly from $10.3 \mathrm{~m}$ to $9.1 \mathrm{~m}$. When the gas pressure decreases from 1.75 to $0.75 \mathrm{MPa}$, the plastic zone radius only decreases by $0.3 \mathrm{~m}$, as shown in Figure 7.

5.3. Influence of Cohesion on the Plastic Zone of Rock Surrounding a Coal Roadway. Figure 8 shows approximate curves of the plastic zone boundary of the circular roadway- 


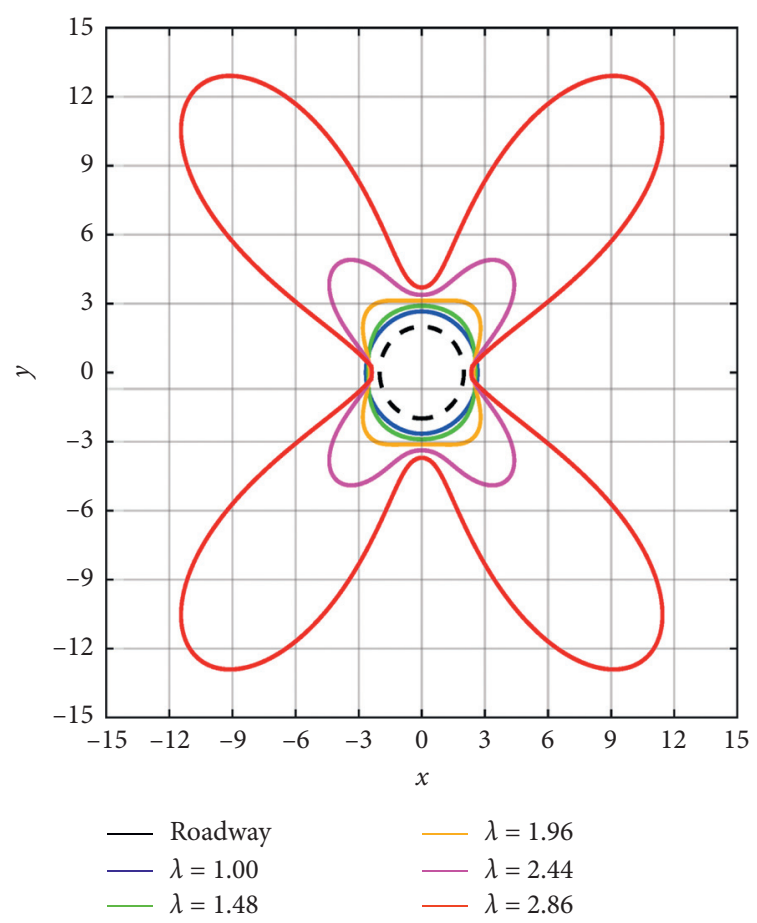

FIGURE 3: Distribution characteristics of plastic zone for various lateral pressure coefficients.

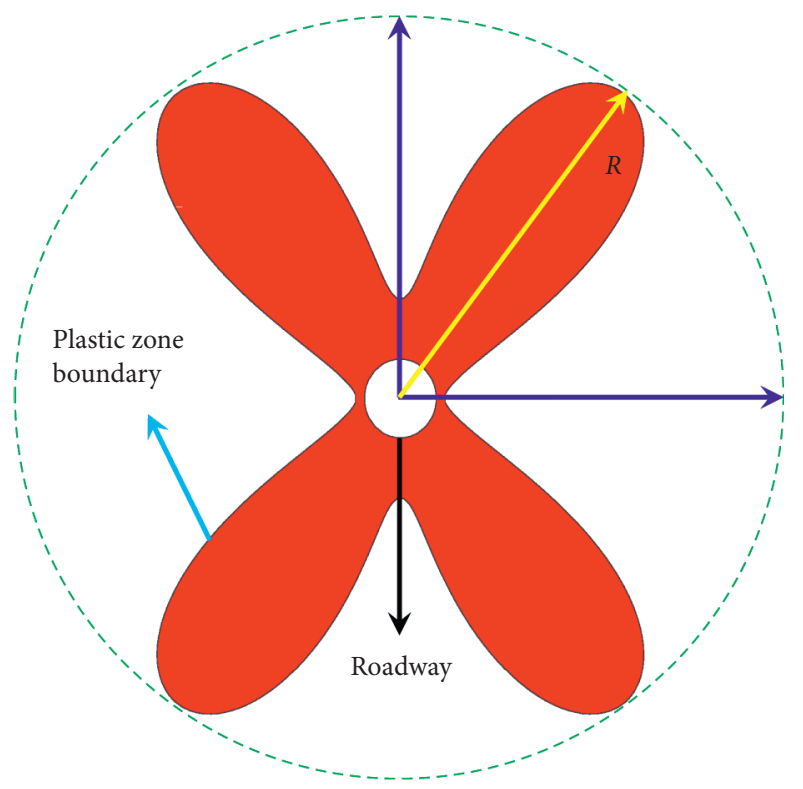

FIgURE 4: Effective radius of plastic zone.

surrounding rock under different cohesion forces, where $P_{1}=19 \mathrm{MPa}, \quad \varphi=25^{\circ}, \quad \mu=0.3, \quad a=2 \mathrm{~m}, \quad P_{i}=0 \mathrm{MPa}$, $P_{a}=P_{g}=0 \mathrm{MPa}$, and $v=0$; the other parameters remain unchanged.

Figures 8(a) and 8(b) indicate that the plastic zone of the surrounding rock of the roadway is circular or elliptical when the lateral pressure coefficient is small. In this case, the cohesion force has little influence on the distribution of the plastic zone, and the plastic zone maintains its original shape and slowly decreases in size as the cohesion increases. It is

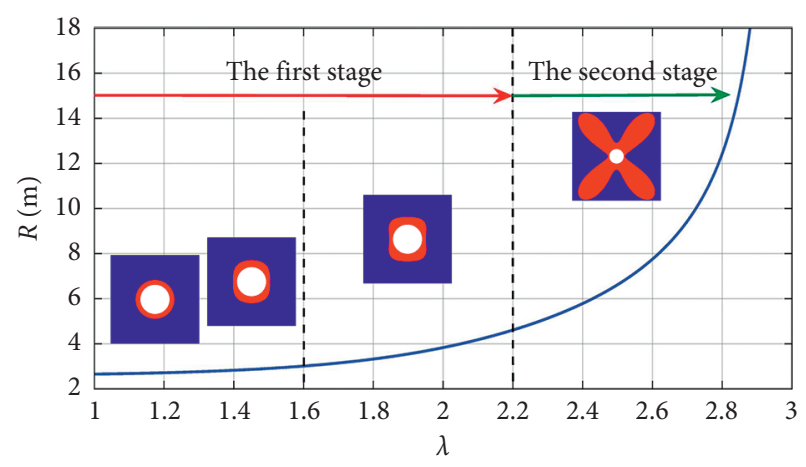

FIGURE 5: Variation of plastic zone radius with respect to the lateral pressure coefficient.

also clear from Figure 9 that the sensitivity of the plastic zone radius to cohesion is relatively weak, with an approximately linear decrease as the cohesion increases. For example, when the cohesion increases from 0.25 to $1.00 \mathrm{MPa}$, the radius of the plastic zone only decreases by $0.16 \mathrm{~m}$.

Figure 8(c) shows that the plastic zone of the surrounding rock of the roadway exhibits an approximate butterfly shape when the cohesion is $0.25 \mathrm{MPa}$. The plastic zone shape when the cohesion increases to $4.00 \mathrm{MPa}$ is a rounded rectangle; that is, an increase in the cohesive force promotes the transformation of the plastic zone from an approximate butterfly to a rounded rectangle. At this stage, the rate of decrease of the plastic zone distribution is different. The four sharp corners of the plastic zone exhibit the fastest rate of decrease, followed by the vertical extent of the plastic zone, with the horizontal extent of the plastic zone exhibiting the smallest rate of decrease.

When the surrounding rock of the roadway presents a butterfly-shaped plastic zone, as shown in Figure $8(\mathrm{~d})$, the four butterfly leaves in the plastic zone are extremely sensitive to cohesion, when the cohesive force is small, and rapidly degrade as the cohesion increases. As the cohesive force continues to increase, the sensitivity of the butterfly leaves to the cohesive force in the plastic zone gradually weakens, and the nonlinear relationship between the two gradually changes to an approximately linear relationship. If the cohesion increases from 0.25 to $1.00 \mathrm{MPa}$, the radius of the plastic zone decreases rapidly from $18.04 \mathrm{~m}$ to $12.86 \mathrm{~m}$. When the cohesion increases from 10.00 to $10.75 \mathrm{MPa}$, the plastic zone radius only decreases by $0.08 \mathrm{~m}$, as shown in Figure 9.

5.4. Influence of Internal Friction Angle on Plastic Zone of Rock Surrounding a Coal Roadway. Figure 10 shows approximate curves of the plastic zone boundary of the circular roadwaysurrounding rock under different internal friction angles, where $P_{1}=19 \mathrm{MPa}, c=3 \mathrm{MPa}, \mu=0.3, a=2 \mathrm{~m}, P_{i}=0 \mathrm{MPa}$, $P_{a}=P_{g}=0 \mathrm{MPa}$, and $v=0$; the other parameters remain unchanged.

Figure 10 has a similar pattern to that in Figure 8 . As shown in Figures 10(a) and 10(b), the internal friction angle has little effect on the distribution of the circular or elliptical plastic zone, and the plastic zone maintains its original shape 


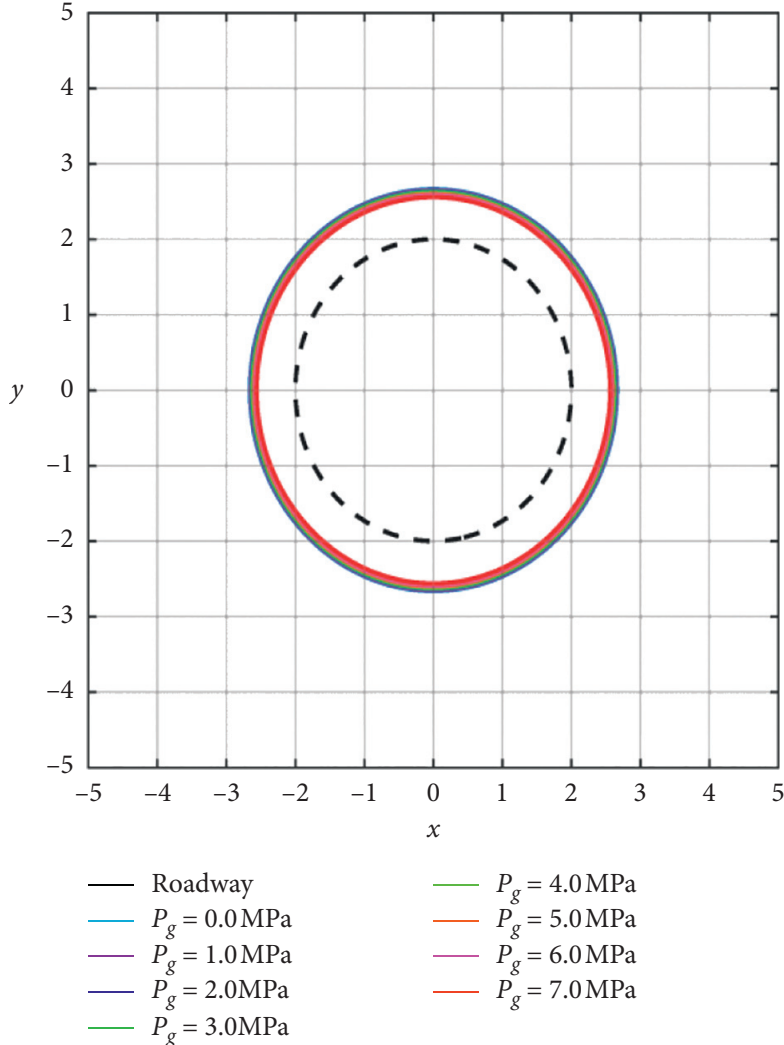

(a)
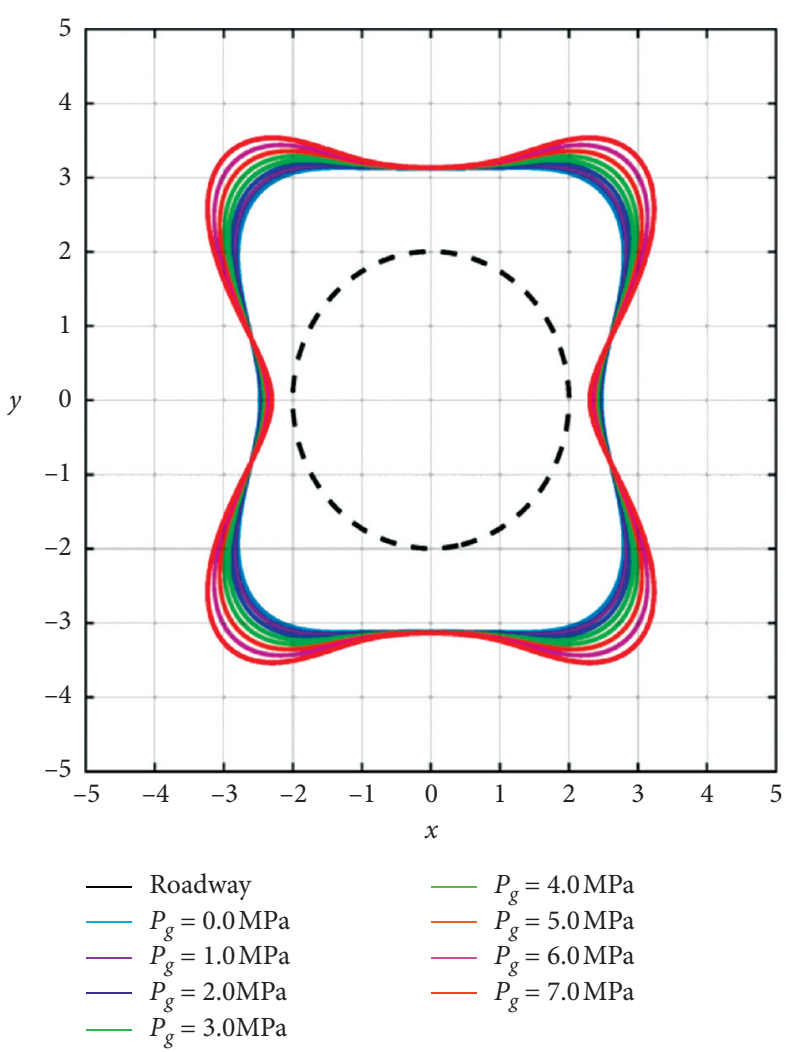

(c)

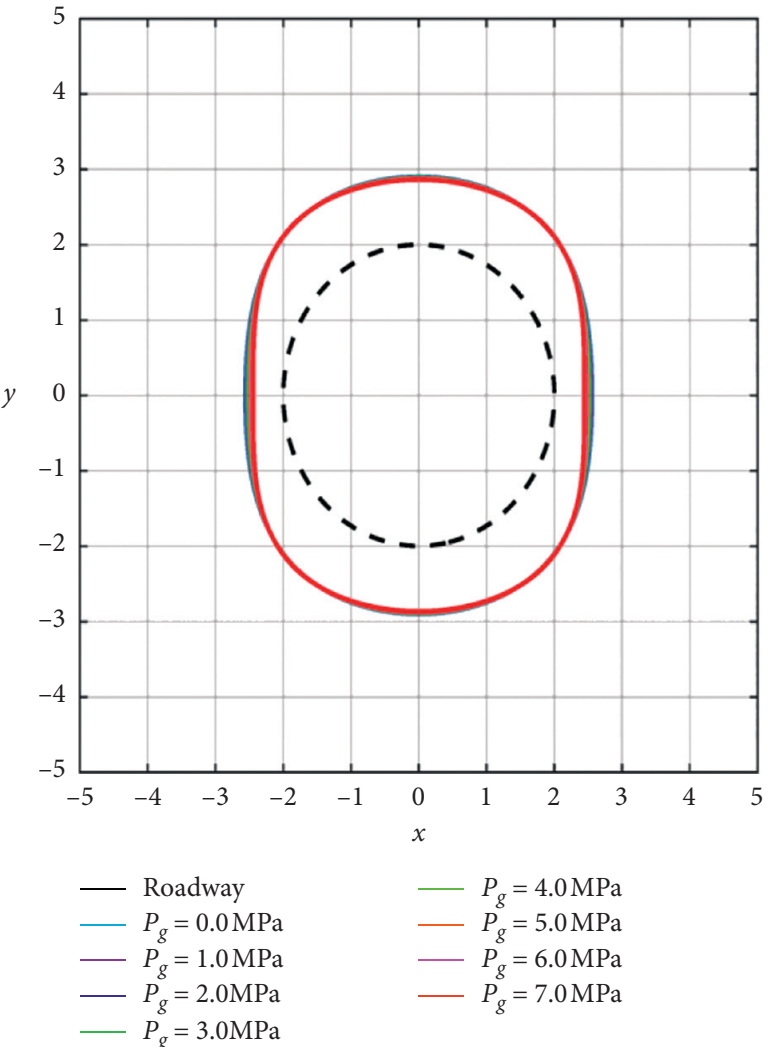

(b)

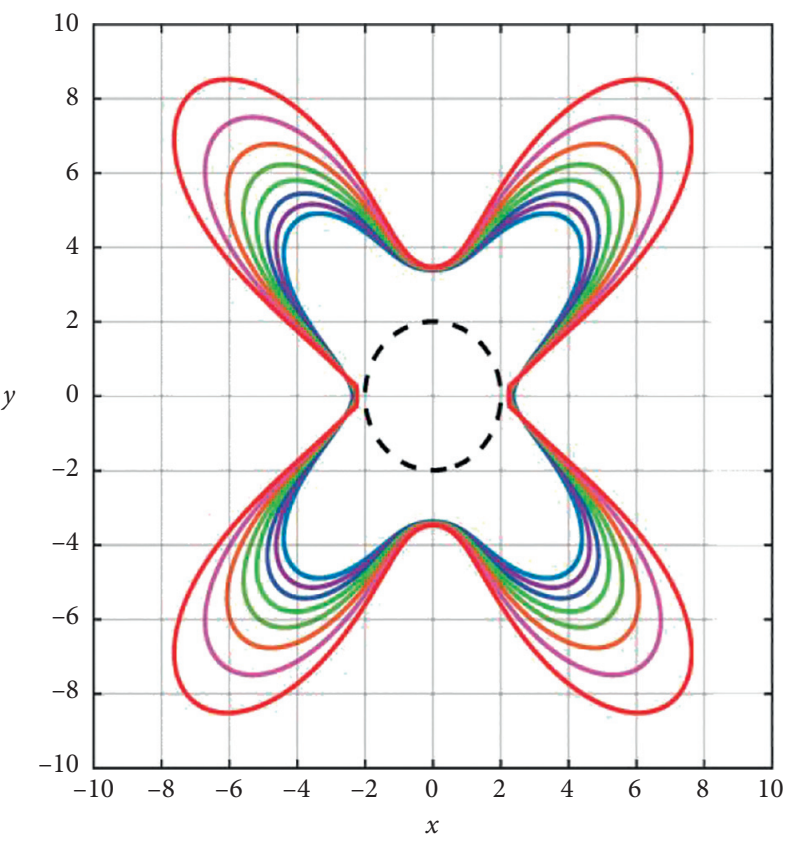

- Roadway
$-P_{g}=0.0 \mathrm{MPa}$
$-P_{g}=1.0 \mathrm{MPa}$
$-P_{g}=2.0 \mathrm{MPa}$
$-P_{g}=3.0 \mathrm{MPa}$

$-P_{g}=4.0 \mathrm{MPa}$

- $P_{g}=5.0 \mathrm{MPa}$

- $P_{g}=6.0 \mathrm{MPa}$

$-P_{g}=7.0 \mathrm{MPa}$

(d)

FIGURE 6: Distribution of plastic zone for various gas pressures. (a) $\lambda=1.00$. (b) $\lambda=1.48$. (c) $\lambda=1.96$. (d) $\lambda=2.44$. 


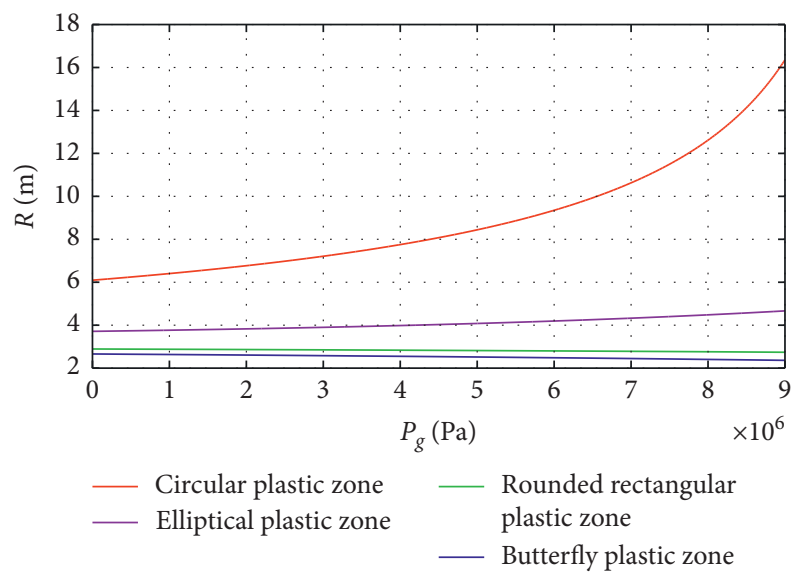

Figure 7: Variation of plastic zone radius with respect to gas pressure.

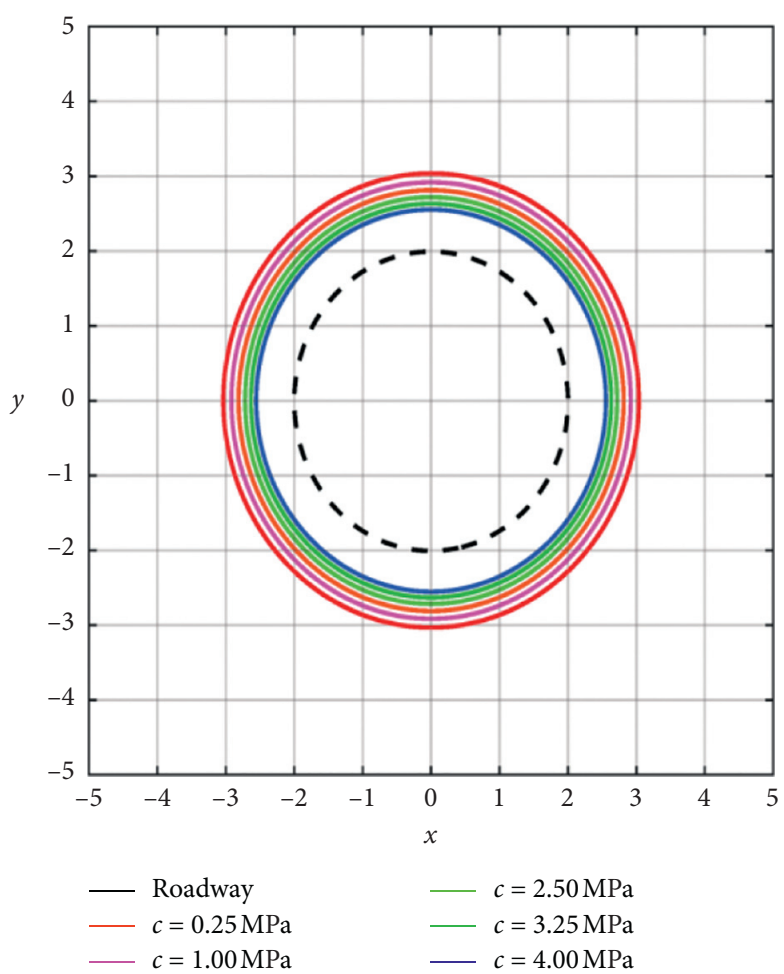

(a)

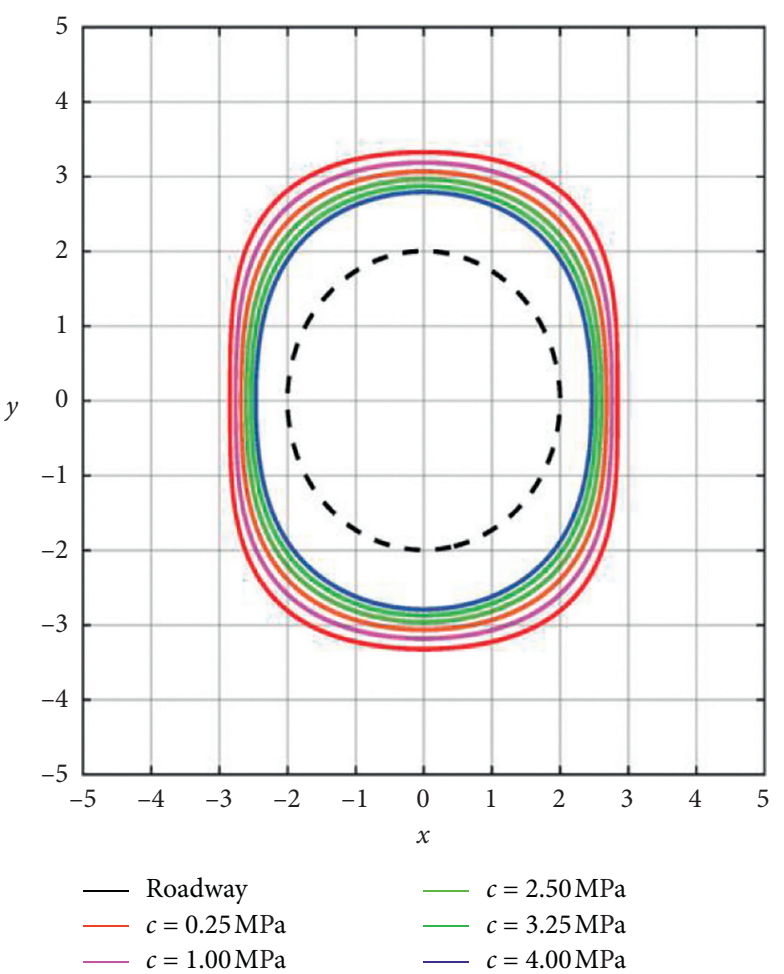

(b)

FIgURE 8: Continued. 


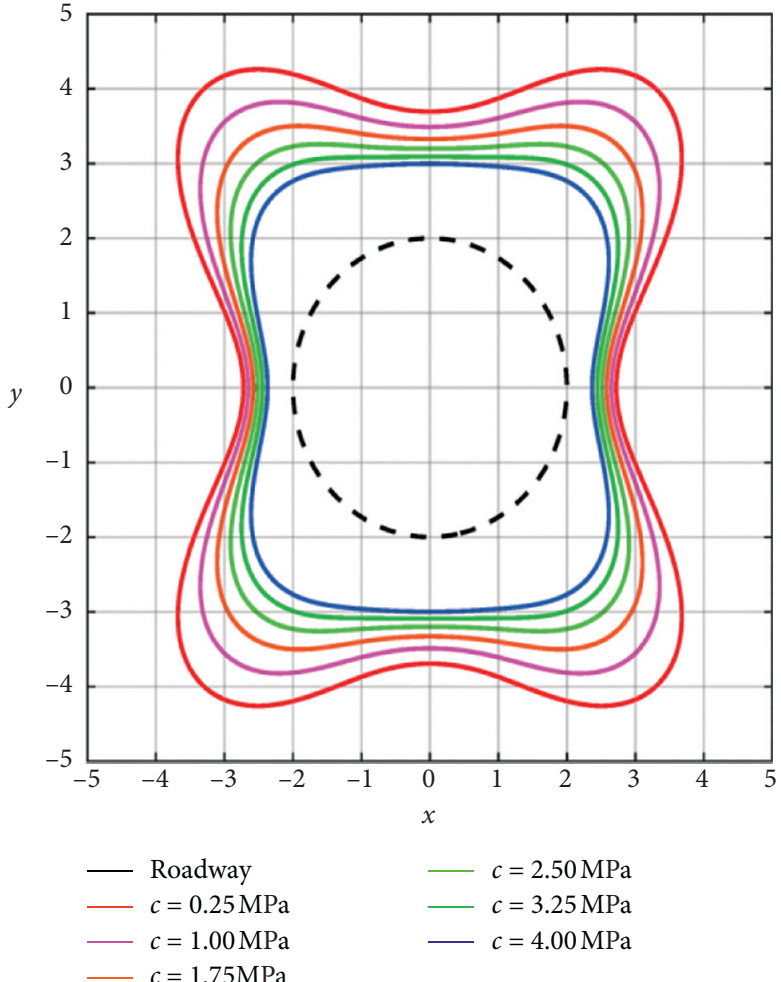

(c)

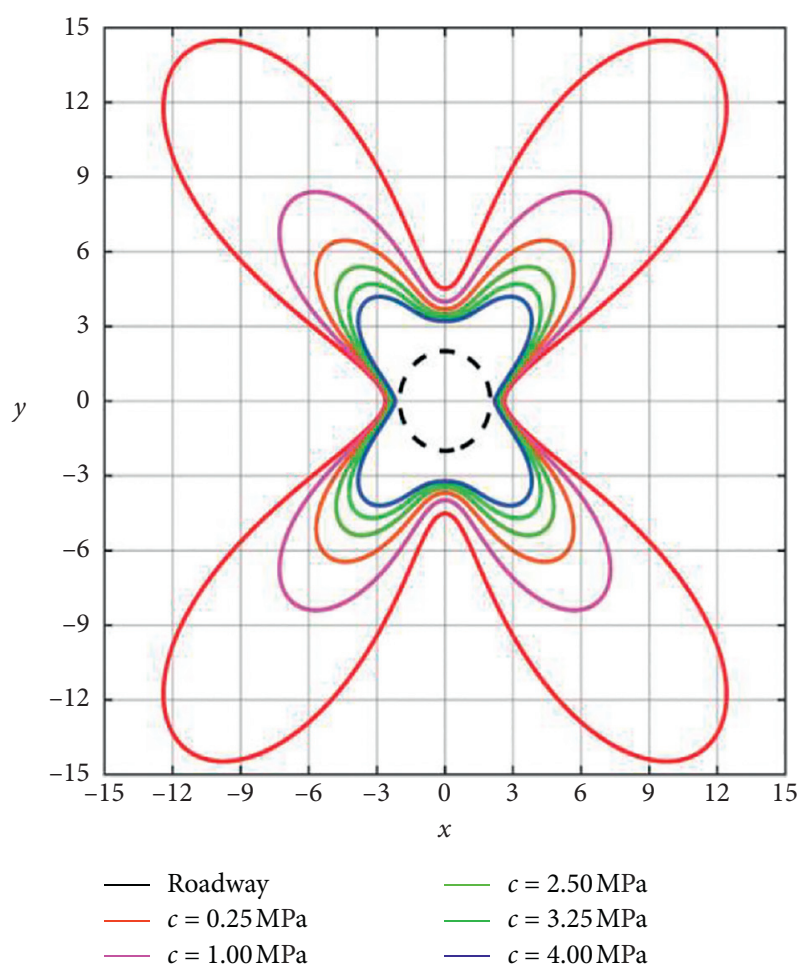

(d)

Figure 8: Distribution of plastic zone for various cohesive forces. (a) $\lambda=1.00$. (b) $\lambda=1.48$. (c) $\lambda=1.96$. (d) $\lambda=2.44$.

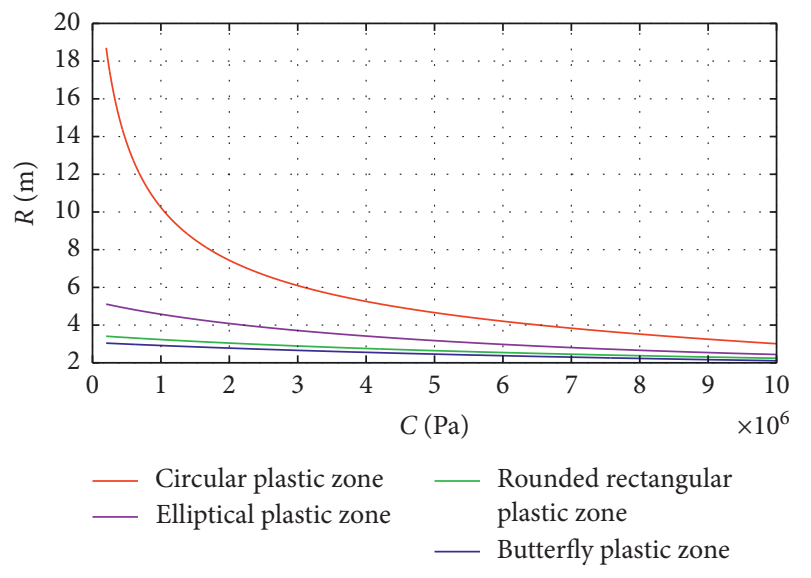

FIgURE 9: Change of radius of plastic zone with respect to cohesion.

and slowly decreases in size as the internal friction angle increases. The sensitivity of the radius of the plastic zone to the internal friction angle is also relatively weak and tends to decrease linearly as the internal friction angle increases. For example, with $\lambda=1.48$, the radius of the plastic zone only decreases by $0.20 \mathrm{~m}$ when the internal friction angle increases from 20 to $23^{\circ}$, as shown in Figure 11 .

It is apparent from Figure 10(c) that when the plastic zone of the surrounding rock of the roadway is rectangular with rounded corners, a continuous increase in the internal friction angle promotes the transformation to an elliptical plastic zone, whereas a continuous reduction promotes the transformation to an approximate butterfly shape. For example, when the internal friction angle is $26^{\circ}$, the plastic zone is rectangular with rounded corners. When this value increases to $35^{\circ}$, the shape of the plastic zone becomes elliptical, and when it decreases to $20^{\circ}$, the shape of the plastic zone is an approximate butterfly. In addition, the rate of change of each part of the plastic zone distribution is different. The four sharp corners change the fastest, followed by the vertical extent of the plastic zone, and finally the horizontal extent of the plastic zone.

When the surrounding rock of the roadway presents a butterfly-shaped plastic zone, as shown in Figure 10(d), the 

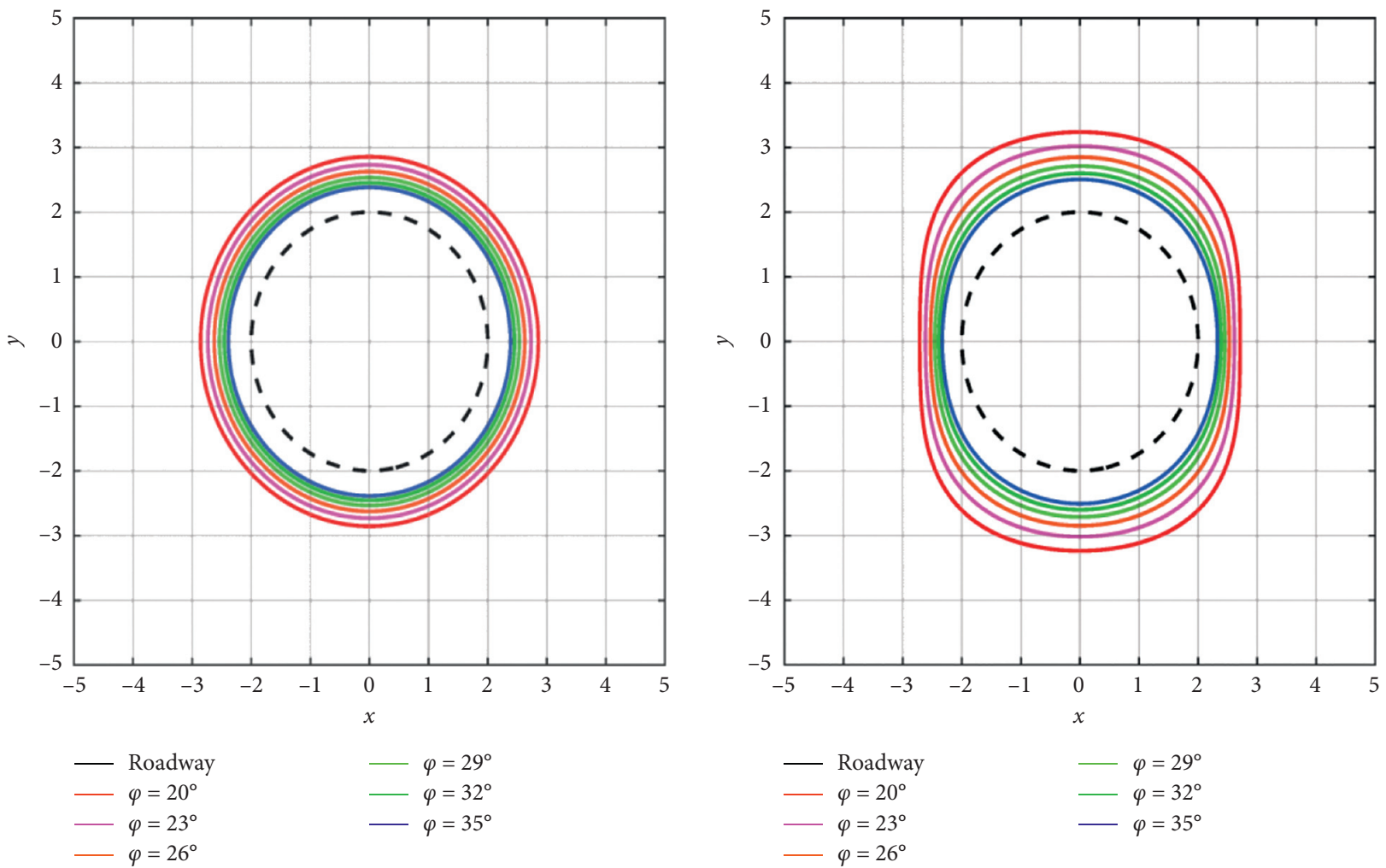

(a)

(b)
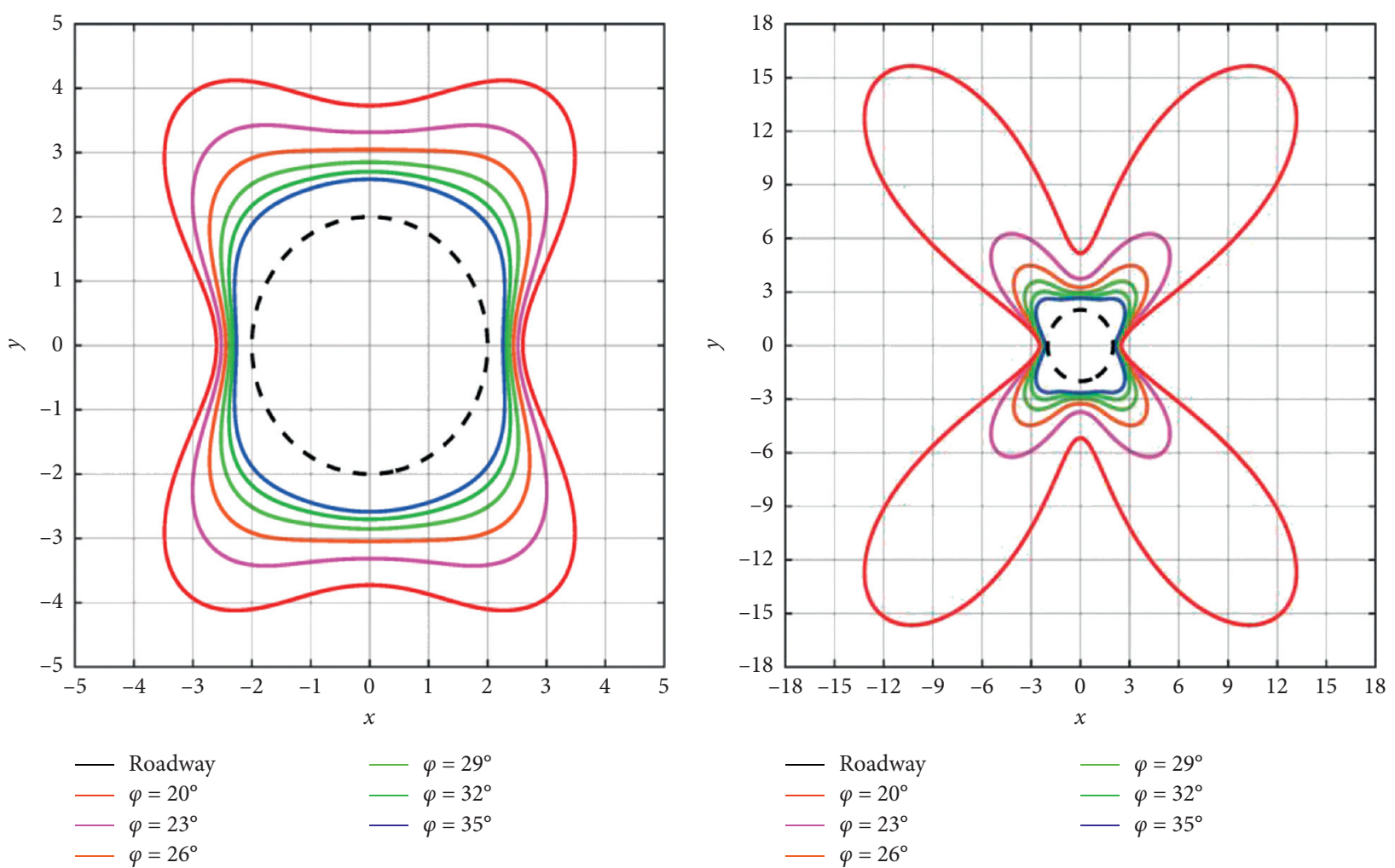

$\begin{aligned}-\varphi & =29^{\circ} \\ -\varphi & =32^{\circ} \\ -\varphi & =35^{\circ}\end{aligned}$

- Roadway
$\varphi=20^{\circ}$
$-\varphi=23^{\circ}$
$\varphi=26^{\circ}$

$-\varphi=29^{\circ}$

$-\varphi=32^{\circ}$

$-\varphi=35^{\circ}$

(c)

(d)

Figure 10: Plastic zone distribution characteristics for various internal friction angles. (a) $\lambda=1.00$. (b) $\lambda=1.48$. (c) $\lambda=1.96$. (d) $\lambda=2.44$. 


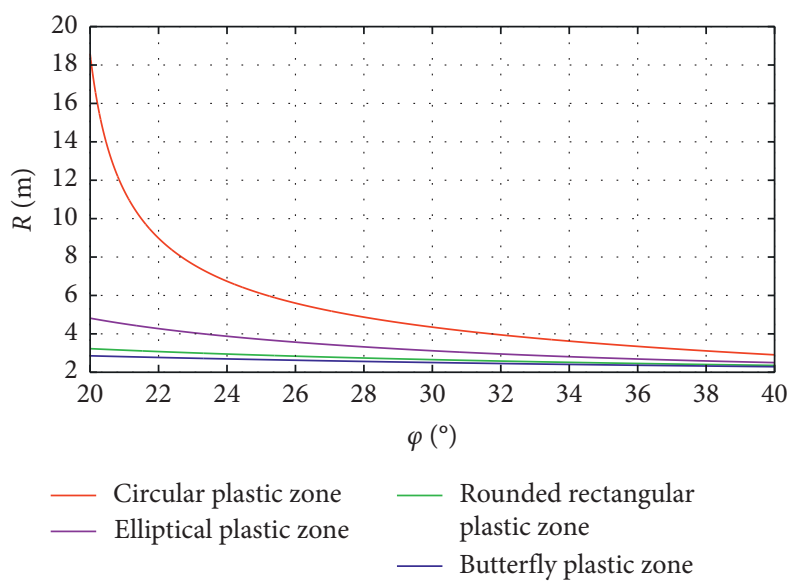

Figure 11: Variation of the radius of the plastic zone with respect to the friction angle.

four butterfly leaves in the plastic zone are extremely sensitive to the internal friction angle, when this angle is small, and degrade rapidly as the internal friction angle increases. With the continuous increase of the internal friction angle, the sensitivity of the butterfly blades in the plastic zone to the internal friction angle gradually weakens, and the nonlinear relationship between the two gradually becomes an approximately linear relationship. If the internal friction angle increases from 20 to $23^{\circ}$, the radius of the plastic zone decreases from $19.35 \mathrm{~m}$ to $7.80 \mathrm{~m}$, whereas an increase from 45 to $48^{\circ}$ only reduces the radius by $0.16 \mathrm{~m}$, as shown in Figure 11.

5.5. Influence of Support Strength on Plastic Zone of Rock Surrounding a Coal Roadway. Figure 12 shows approximate curves of the plastic zone boundary of the circular roadwaysurrounding rock under different supporting strengths, where $P_{1}=19 \mathrm{MPa}, c=3 \mathrm{MPa}, \mu=0.3, \quad a=2 \mathrm{~m}, \varphi=25^{\circ}$, $P_{a}=P_{g}=0 \mathrm{MPa}$, and $v=0$; the other parameters remain unchanged.

Figures 12 and 13 show that when the mechanical properties and stress environment of the surrounding rock of the roadway are constant, increasing the support strength at the free face of the roadway has a limited effect on the distribution and range of the plastic zone. The radius of the plastic zone decreases as the support strength increases, but the rate of decrease is extremely slow. For example, when $\lambda=2.44$, the radius of the plastic zone only decreases by $0.1 \mathrm{~m}$ when the support strength increases from 0.0 to $5.0 \mathrm{MPa}$. It must be emphasized that the support strength discussed in this article refers to the support strength for the free face of the roadway. Its function is mainly to prevent the deformation of the roadway-surrounding rock and the expansion of the plastic zone, rather than to change the strength of the roadway-surrounding rock mass. The main functions in underground engineering are for shotcrete support, masonry support, steel arch support, and so on. Therefore, for the control of gas-coal roadways, it is necessary to increase the support strength and to increase the strength of the surrounding rock mass, thereby restraining the expansion of the plastic zone and ensuring the normal use of gas-coal roadways.

\section{Discussion}

The theoretical analysis presented in the previous section has found that the plastic zone of the surrounding rock of a roadway mainly has four distribution patterns: circular, elliptical, rounded rectangle, and butterfly. The lateral pressure coefficient, gas pressure, surrounding rock cohesion, and internal friction angle all affect the distribution and range of the plastic zone of the surrounding rock of the roadway. For the support problem of high-gas-coal roadway-surrounding rock, targeted support should be designed according to the shape and range of the plastic zone. The length of the anchor rod and the anchor cable must be greater than the range of the plastic zone, thus reinforcing the support of the leaves of butterfly-shaped plastic zones, reducing the gas pressure, and improving the strength and overall stability of the surrounding rock mass.

The research results presented in this paper will contribute to the improvement of gas drainage efficiency. The plastic zone effectively increases the permeability of highgas-coal seams, and the plastic zone is the main channel for gas flow. When there is a butterfly-shaped plastic zone in the coal seam, the distance between the drainage boreholes should be designed scientifically and reasonably. The butterfly blades in the plastic zone between the drainage boreholes should be connected to each other to avoid the appearance of blind areas. When there is a nonbutterfly plastic zone in the coal seam, its range can be expanded by means of hydraulic fracturing and blasting fracturing, thereby increasing the permeability of the coal seam and increasing the gas drainage rate. 


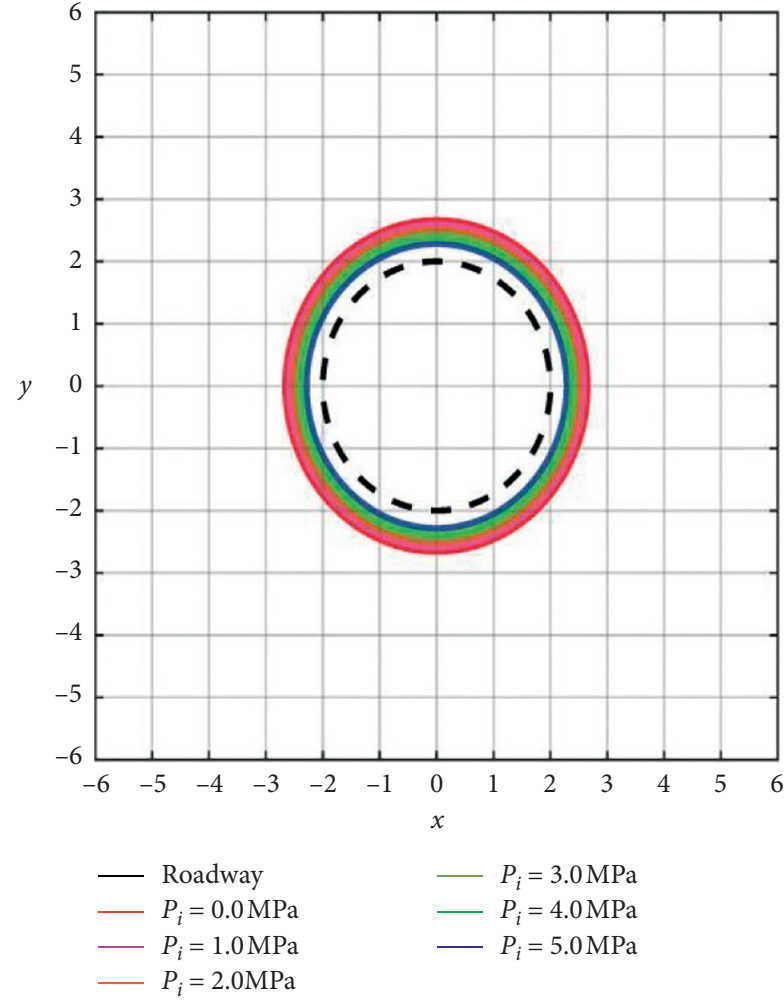

(a)

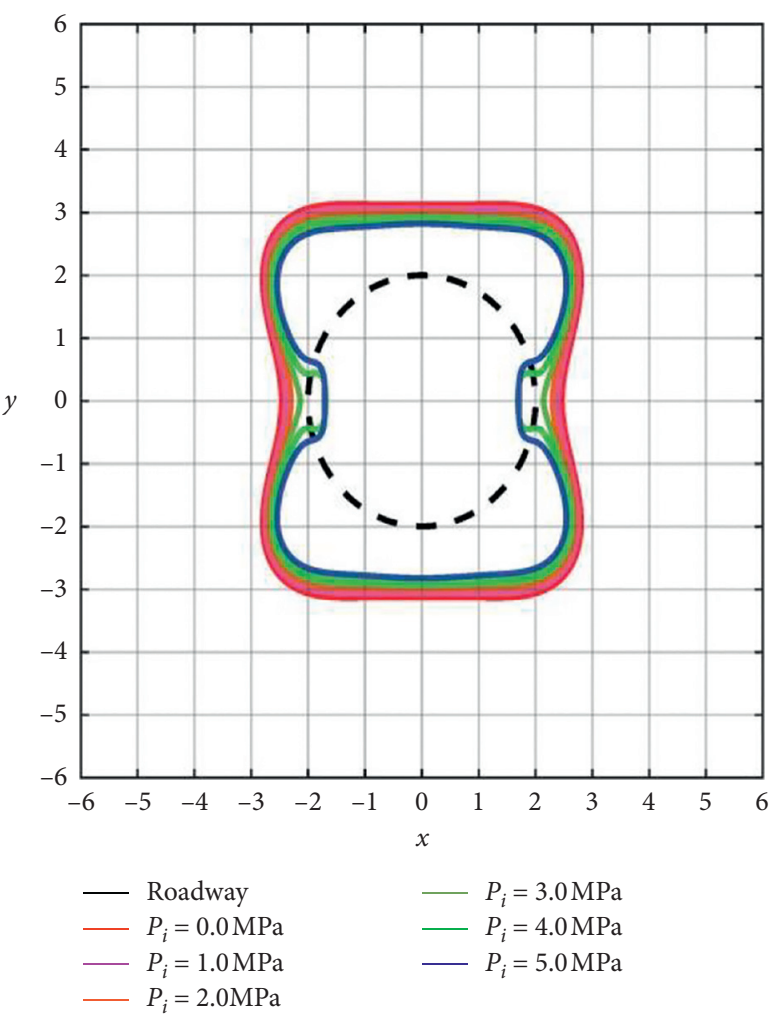

(c)

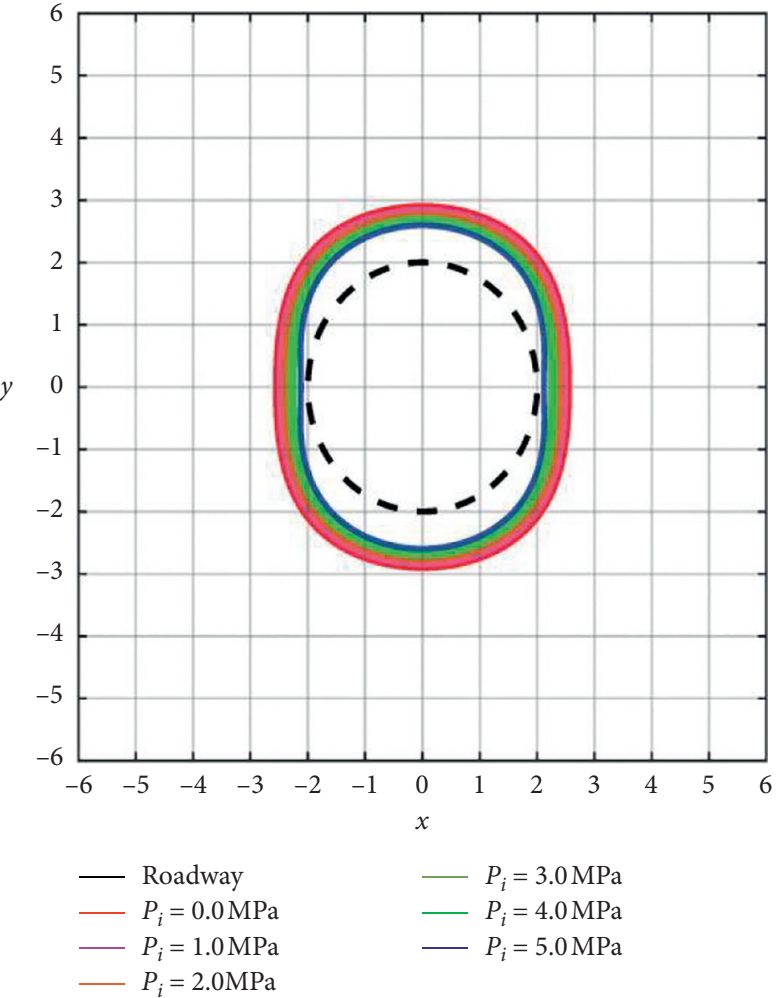

(b)

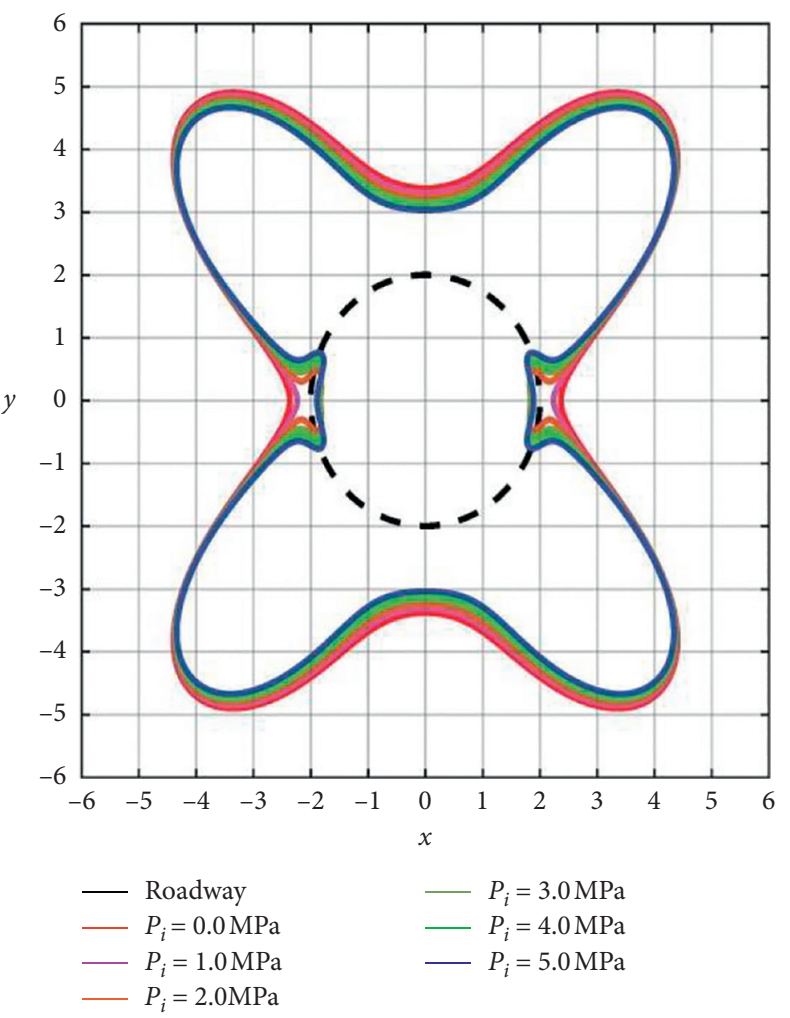

(d)

Figure 12: Relationship between tunnel radius and shape of plastic zone. (a) $\lambda=1.00$. (b) $\lambda=1.48$. (c) $\lambda=1.96$. (d) $\lambda=2.44$. 


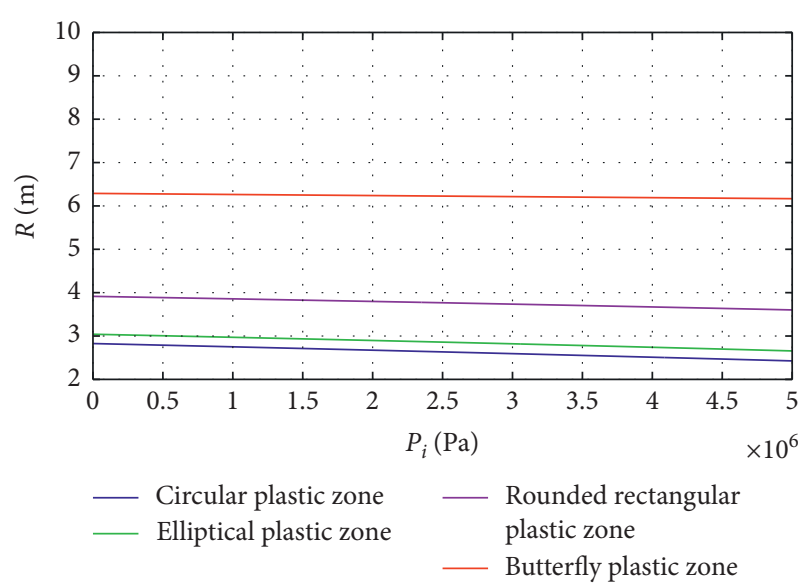

FIGURE 13: Relationship between tunnel radius and radius of plastic zone.

\section{Conclusions}

(1) The implicit equation for the boundary of the plastic zone in the surrounding rock of a gas-coal roadway has been obtained, and the plastic zone was found to have four main distribution patterns: circular, elliptical, rounded rectangle, and butterfly.

(2) Circular and elliptical plastic zones are less sensitive to gas pressure, cohesion, and internal friction angle, whereas butterfly-shaped plastic zones are extremely sensitive to these variables. The main manifestation is that the four butterfly leaves rapidly degenerate as the gas pressure decreases or as the cohesion and internal friction angle increase; larger butterfly leaves tend to degenerate faster.

(3) The rounded rectangle is a transitional plastic zone between the butterfly and elliptical plastic zones. Changes in gas pressure, cohesion, and internal friction angle can all promote the transformation of the rounded rectangular plastic zone to the butterflyshaped plastic zone or the elliptical plastic zone.

(4) The support strength at the roadway free face has a limited impact on the plastic zone. The support strength does not change the distribution of the plastic zone but does affect its range.

\section{Data Availability}

All the data generated or published during the study are included within the article; no other data were used to support this study.

\section{Conflicts of Interest}

The authors declare that they have no conflicts of interest regarding the publication of this paper.

\section{Acknowledgments}

This work was financially supported by the National Natural Science Foundation of China (Grant nos. 51804109,
51874130, 51974118, and 51774133). The authors are grateful for this financial support.

\section{References}

[1] J. F. Cui, W. J. Wang, C. Yuan, L. M. Cao, Y. N. Guo, and L. Fan, "Study on deformation mechanism and supporting countermeasures of compound roofs in loose and weak coal roadways," Advances in Civil Engineering, vol. 2020, Article ID 8827490, 13 pages, 2020.

[2] C. Yuan, Y. N. Guo, W. J. Wang, L. M. Cao, L. Fan, and C. Huang, "Study on "triaxial loading-unloading-uniaxial loading" and microscopic damage test of sandstone," Frontiers in Earth Science, vol. 8, p. 11, 2020.

[3] L. Jiang, A. Sainoki, H. S. Mitri, N. Ma, H. Liu, and Z. Hao, "Influence of fracture-induced weakening on coal mine gateroad stability," International Journal of Rock Mechanics and Mining Sciences, vol. 88, pp. 307-317, 2016.

[4] C. Yuan, L. Fan, J. F. Cui, and W. J. Wang, "Numerical simulation of the supporting effect of anchor rods on layered and nonlayered roof rocks," Advances in Civil Engineering, vol. 2020, Article ID 4841658, 14 pages, 2020.

[5] M. R. Zareifard and A. Fahimifar, "Analytical solutions for the stresses and deformations of deep tunnels in an elastic-brittleplastic rock mass considering the damaged zone," Tunnelling and Underground Space Technology, vol. 58, pp. 186-196, 2016.

[6] N. J. Ma, J. Li, and Z. Q. Zhao, "Distribution of the deviatoric stress field and plastic zone in circular roadway surrounding rock," Journal of China University of Mining and Technology, vol. 44, no. 2, pp. 206-213, 2015.

[7] C. C. Xia, C. Xu, Y. P. Liu, and C. L. Han, "Elastoplastic solution of deep buried tunnel considering strain-softening characteristics based on GZZ strength criterion," Chinese Journal of Rock Mechanics and Engineering, vol. 37, pp. 2468-2477, 2018.

[8] Z. H. Zhao, Y. L. Tan, S. J. Chen, Q. Ma, and X. J. Gao, "Theoretical analyses of stress field in surrounding rocks of weakly consolidated tunnel in a high-humidity deep environment," International Journal of Rock Mechanics \& Mining Sciences, vol. 122, p. 11, Article ID 104064, 2019.

[9] X. Liu, Q. Fang, D. L. Zhang, and Y. Liu, "Energy-based prediction of volume loss ratio and plastic zone dimension of shallow tunnelling," Computers and Geotechnics, vol. 118, p. 13, Article ID 103343, 2020.

[10] X. P. Zhou and J. L. Li, "Hoek-Brown criterion applied to circular tunnel using elastoplasticity and in situ axial stress," Theoretical and Applied Fracture Mechanics, vol. 56, no. 2, pp. 95-103, 2011.

[11] Y. C. Ma, A. Z. Lu, X. T. Zeng, and H. Cai, "Analytical solution for determining the plastic zones around twin circular tunnels excavated at great depth," International Journal of Rock Mechanics \& Mining Sciences, vol. 136, p. 14, Article ID 104475, 2020.

[12] H. Zhou, J. Gao, K. Han, and Y. Cheng, "Permeability enhancements of borehole outburst cavitation in outburst-prone coal seams," International Journal of Rock Mechanics and Mining Sciences, vol. 111, pp. 12-20, 2018.

[13] W. Zhao, K. Wang, Y. Ju et al., "Influence of the roadway exposure time on the accuracy of gas content measurements in reconstructed and extended mines," Process Safety and Environmental Protection, vol. 142, pp. 109-117, 2020.

[14] T. Liu, B. Lin, X. Fu, and C. Zhu, "Modeling air leakage around gas extraction boreholes in mining-disturbed coal 
seams," Process Safety and Environmental Protection, vol. 141, pp. 202-214, 2020.

[15] Y. Zhang, Q. Zou, and L. Guo, "Air-leakage model and sealing technique with sealing-isolation integration for gas-drainage boreholes in coal mines," Process Safety and Environmental Protection, vol. 140, pp. 258-272, 2020.

[16] J.-Z. Zhang, X.-P. Zhou, and P. Yin, "Visco-plastic deformation analysis of rock tunnels based on fractional derivatives," Tunnelling and Underground Space Technology, vol. 85, pp. 209-219, 2019.

[17] M.-F. Xu, S.-C. Wu, Y.-T. Gao, J. Ma, and Q.-L. Wu, “Analytical elastic stress solution and plastic zone estimation for a pressure-relief circular tunnel using complex variable methods," Tunnelling and Underground Space Technology, vol. 84, pp. 381-398, 2019.

[18] E. Kabwe, M. Karakus, and E. K. Chanda, "Proposed solution for the ground reaction of non-circular tunnels in an elasticperfectly plastic rock mass," Computers and Geotechnics, vol. 119, p. 15, Article ID 103354, 2019.

[19] Z. L. Xu, Concise Course of Elasticity, Higher Education Press, Beijing, China, 4th edition, 2013.

[20] P. Li and S. J. Miao, "Analysis and application of in-situ stress in metal mining area of Chinese mainland," Chinese Journal of Engineering, vol. 39, no. 3, pp. 323-334, 2017.

[21] W. Yu, B. Pan, F. Zhang, S. Yao, and F. Liu, "Deformation characteristics and determination of optimum supporting time of alteration rock mass in deep mine," KSCE Journal of Civil Engineering, vol. 23, no. 11, pp. 4921-4932, 2019. 